VOLUME 3

NUMBER 1

SPRING 2007

\section{Contents}

\section{Editorial}

The debate needs to cool down Malcolm Hollis

\section{Papers}

CONREPNET: Performance-based approach to the remediation of reinforced concrete structures: Achieving durable repaired concrete structures

Stuart Matthews

Value for money? Fraud in the property market Sophie Stallworthy

Condition rating of $\mathrm{RC}$ structures: A case study Dario Coronelli

A survey of roof failures in Oyo State of Nigeria Yahaya Mijinyawa, Sunday Olufemi Adesogan and Olugbenga Gideon Ogunkoya

Practical implications of GPR investigation using 3D data reconstruction and transmission tomography Lukasz Topczewski, Francisco M. Fernandes, Paulo J.S. Cruz and Paulo B. Lourenço

Comparison of nondestructive testing: Infrared thermography, electrical resisitivity and capacity methods for assessing a reinforced concrete structure Colette Sirieix, Jean François Lataste, Denys Breysse, Samuel Naar and Xavier Dérobert 


\title{
Practical implications of GPR investigation using 3D data reconstruction and transmission tomography
}

Received (in revised form): 6th February, 2007

\section{Lukasz Topczewski}

graduated with an MSc in Civil Engineering from the Warsaw University of Technology, Poland, in 2003. Currently, he is a researcher and PhD student in the Department of Civil Engineering of the University of Minho, Guimarães, Portugal. His main research areas are the inspection and diagnosis of concrete and masonry structures using GPR and sonic techniques. He is an active member of the ‘Sustainable Bridges' European Project.

\section{Francisco M. Fernandes}

graduated in Civil Engineering from the University of Minho in 2001 and obtained his PhD in 2006. Currently, he is a post-doctoral researcher in the Department of Civil Engineering, University of Minho, Guimarães, Portugal. His main research interests include the inspection and diagnosis of historical structures with non-destructive (GPR) and minor-destructive techniques (micro drilling) and the application of GPR in concrete structures, pavements and underground utilities.

\section{Paulo J.S. Cruz}

is an associate professor in the Department of Civil Engineering, University of Minho, Guimarães, Portugal and is President of the Autonomous Department of Architecture at the University of Minho.

\section{Paulo B. Lourenço}

is an associate professor and Director of the Department of Civil Engineering, University of Minho, Guimarães, Portugal.

Correspondence: Francisco M. Fernandes, Department of Civil Engineering, University of Minho, Guimarães 4800-058, Portugal; Tel: + 351962562 940; Fax: + 351253510 217; E-mail: fmcpf@civil.uminho.pt

\begin{abstract}
Non-destructive investigation using ground penetrating radar is becoming more popular in the inspection of civil structures. Currently, traditional 2D imaging is used as a preliminary tool to find possible areas of interest for more detailed inspection, which can be accomplished by more advanced techniques like 3D image reconstruction or tomography. In this paper, a general overview of the work done at University of Minho regarding these techniques is presented, together with their limitations and advantages over typical radargrams, with implications for civil engineering applications. For this purpose, data acquisition on two large masonry walls and one large concrete specimen have been carried out, using reflection mode, 3D reconstruction and transmission tomography. The specimens have been specially built for non-destructive inspection techniques testing, incorporating different materials and internal voids. Radar tomography and 3D image reconstruction techniques provided much more detailed information about structural integrity and shapes and location of the voids, when compared to 2D imaging originally used for potential target identification. Journal of Building Appraisal (2007) 3, 59-76. doi:10.1057/palgrave.jba.2950060
\end{abstract}




\section{Keywords:}

NDT, GPR, 3D reconstruction, tomography, concrete, masonry, maintenance, inspection

\section{INTRODUCTION}

Exhaustive preliminary inspections using non-destructive inspection techniques (NDT) are becoming common in restoration and retrofitting projects as well as within maintenance programmes of civil engineering structures. A widely known NDT technique is the ground penetrating radar (GPR), which is a very attractive option as it can reliably acquire non-visible information without causing damage to the structure, which is often critical due to conservation and economic factors.

Despite the fact that practitioners are becoming more conscious of the potential of this non-destructive technique, its use is still not frequent outside the academic community, at least for structural (non-geotechnical) applications. In Portugal, only a small number of investigative institutes possess the necessary equipment and use it frequently.

The present paper aims at contributing to the increase of the use of GPR by showing practical examples where the detection capabilities of GPR with high-frequency antennas, powerful software and advanced acquisition techniques were successfully used to detect and diagnose common problems in concrete and masonry structures. The main techniques used in the paper are described in the following section, together with their possibility for applications and limitations. The experimental part of the paper consists of the advanced application of 3D mapping and direct transmission tomographic measurements in specially built specimens to detect anomalies in a simulated portion of a concrete bridge deck and the constitution of complex masonry walls, and to stress the advantages of advanced techniques over traditional 2D radargrams.

\section{Advanced techniques in GPR}

GPR is a non-destructive technique based on emission of electromagnetic energy over a wide range of frequencies ( $25 \mathrm{MHz}$ to $2.2 \mathrm{GHz}$ ). Theoretical background and operative modes of GPR have been described in detail for example, in Daniels (2004). Radar is used commonly in reflection mode to collect data by dragging an antenna on the surface. This information results in 2D radargrams, which is the most frequent technique of analysing radar data. For usual problems such as thickness measurements (Krause et al., 1995), rebar detection (Hugenschmidt, 2002), location of large voids (Maierhofer et al., 2003) and in most building materials (masonry and reinforced concrete), this mode is the most suitable, fastest and cheapest. In other cases, however, individual radargrams might provide insufficient information, being difficult to interpret or failing to detect small objects or defective/damaged areas. This calls for more advanced techniques that can be applied in order to obtain higher quality or additional information.

\section{Method 1: 3D reconstruction}

The first advanced technique is to obtain a $3 \mathrm{D}$ volume of the radar data by acquiring a dense subset of parallel 2D radar profiles. See Valle et al. (2000), Groenenboom et al. (2001) and Kohl et al. (2003) for more in-depth information. Figure 1 illustrates how to acquire adequate data in order to allow a precise reconstruction of the $3 \mathrm{D}$ representative body.

The accurate location of each trace and parallelism between traces is critical to produce accurate $3 \mathrm{D}$ volumes. A good control of the starting and end points allows radargrams with the same length to be collected. The separation between each profile is essential to 


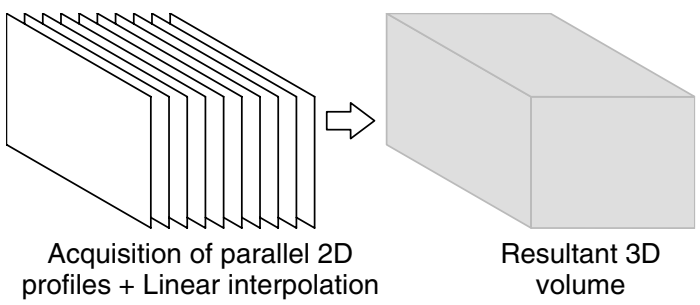

Figure I: Methodology to obtain a 3D volume from 2D data

avoid losing essential information. The smaller the separation between parallel profiles, the more accurate the final data will be, even if this can result in a very large amount of data and related processing time, which might not prove worthwhile due to the significant computer resources and time needed for 3D acquisition and processing. In most practical cases, the Nyquist criterion should be followed (Doerksen, 2002) and a minimal separation of $50 \mathrm{~mm}$ is usually sufficient to obtain good accuracy in structural applications.

The $3 \mathrm{D}$ volume is created by performing a linear interpolation between successive radargrams. This technique has been successfully applied in numerous applications of NDT investigation of civil structures by providing a visualisation of the radar data within the investigated area by showing the results as depth slices (Lualdi et al., 2003) or by providing more realistic images of linear objects, such as pipes, cables, rebars and large voids through isosurfaces (Binda et al., 2003a). Additionally, the technique allows non-specialised radar users to better understand results by providing realistic shapes of embedded features.

\section{Method 2: Tomography}

The second advanced technique described in this paper is denoted by tomography, which was originally developed in medicine and in several other fields (geophysics) with the aim of reproducing the internal structure of an object from measurements collected externally. In geotechnical applications, cross-hole tomography is commonly used to determine the position of cracks in rocky ground and to assess the condition of deep foundation piles. In the case of structural civil engineering, radar tomography is quite a recent technique. It is generally used to map the interior of objects like columns, walls and other elements that can be accessed from two or more sides. Tomography is a rather distinct processing mode, which makes use of direct transmission acquisitions. In this acquisition mode, the transmitter and the receiver antennas are separated and located successively in various positions, in order to entirely cover the area under investigation with electromagnetic rays, being the direct pulse recorded. Figure 2 illustrates an example of tomography of a column where, for each position of the transmitter antenna, the receiver is dragged along the remaining edges of the column in such a way that the cross-section of the column covered with radiowaves is maximised. As the distance between the positions is also known, it is straightforward to calculate the mean radiowave velocity of the appropriate ray path. Special inversion algorithms are used to calculate the velocity or attenuation distributions from the time travel or amplitude information, respectively, to allow the reconstruction of the interior of the solids; see for example Binda et al. (2003b). The image reconstruction from the data can be performed using either iterative or transformation-based algorithms. The most commonly used iterative algorithms are the algebraic reconstruction technique (ART) and the simultaneous iterative reconstructive 


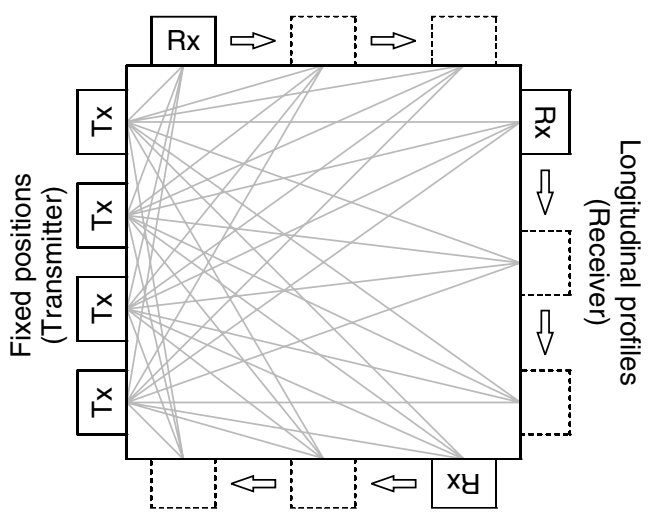

Figure 2: Tomography applied to a square column showing the distribution of transmitters and receivers

technique (SIRT), which are based on the inversion of a single parameter (travel time or amplitude). Additional information about the technique and reconstruction algorithms can be found elsewhere (Kak and Slaney, 1988; Buyukozturk, 1998; Valle et al., 1999; Tronicke et al., 2002; Becht et al., 2004).

Tomography can be used generally to map voids, moisture content and embedded timber elements (Binda et al., 2003b). Owing to the significant time, hardware and software requirements necessary for acquisition, this technique, however, is used only in a given location of the body.

In radar velocity tomography, a typical tomogram shows a velocity distribution inside the cross-section of the structure. In the case of electromagnetic waves, areas with high velocity can represent materials with low dielectric constant, while areas with a lower velocity can represent materials with a higher dielectric constant. Areas with a propagation velocity above $0.2 \mathrm{~m} / \mathrm{ns}$ frequently represent air voids, while areas with a velocity around zero indicate, generally, the presence of steel or of very high amounts of moisture. Similarly, a radar attenuation (slowness) tomography is able to distinguish materials with a high attenuation (eg water, sea water, high chloride content or ferromagnetic materials) from materials with a low attenuation (air voids and dry timber).

\section{Limitations and practical requirements}

Before applying advanced radar techniques, one should be aware of the specific requirements of these techniques and should analyse the parameters involved in the investigations, which might affect the data acquisition and processing. Non-destructive techniques can be expensive, despite their advantages. In the case of GPR, the following items must be considered in the process of selecting the technique:

1. Type and nature of the materials to be investigated, as electromagnetic waves propagate at different speeds in different kinds of natural and man-made materials.

2. Nature of the targets of the investigation (reinforcement, moisture, voids, etc). Generally, a very dense grid of reinforcement produces poor or no results at all.

3. Preliminary assessment of the presence of moisture (eg due to rain or rising damp), as it affects severely the GPR performance and can prevent the acquisition of suitable data.

4. Careful assessment of the time needed to acquire sufficient data to obtain the requested results. Too much data can increase processing time and costs unnecessarily.

5. Verify the conditions of access to the testing site and the areas to be investigated. 
In case of tomography measurements, additional requirements need to be addressed, namely:

1. The necessity of access from two or more sides. The reconstruction algorithms used for data processing are most suitable in cases where two or more sides of the structure are accessible and covered by electromagnetic rays.

2. The higher qualifications and experience of the radar operator, especially for data processing.

3. The precision of the measurements is crucial in order to obtain uncluttered tomograms. Generally, the step between each fixed station must be chosen specifically for each case taking into account the operator's expertise.

\section{Practical implications for civil engineering industry}

Quality control and diagnosis by non-destructive inspection using GPR can result in an increase in safety of structures and in a global reduction of associated costs for future repair and replacement. Thus, there are significant implications for the success of GPR techniques for the civil engineering industry, such as:

1. Performance evaluation and updating of the assumptions made in the models used for the assessment of structural safety in existing structures for the design of new structures.

2. Validation of geometry surveys used for assessment or retrofit actions of existing structures and quality control of new structures.

3. Damage detection of the structure or infrastructure caused by inadequate or faulty workmanship or any external action.

\section{Application 1: Analysis of defects in concrete using 3D reconstruction}

\section{Description of the test specimen and methodology}

The concrete specimen was specially built to simulate a part of a typical concrete bridge deck, being square in plan, with dimensions of $2.50 \times 2.50 \mathrm{~m}$, and a thickness of $0.32 \mathrm{~m}$. Additional elements were placed inside, chosen from typical elements used in the construction of structural elements in reinforced and prestressed concrete bridge decks. Typical defects and anomalies that may occur during construction were also reproduced in the specimen. A general view of the features inside the slab before being filled with concrete is illustrated in Figure 3a, while a general view of the cast specimen is illustrated in Figure $3 b$.

Three PVC tendon ducts (one with $110 \mathrm{~mm}$ diameter and two with $35 \mathrm{~mm}$ diameter) were placed inside the slab. The larger tendon duct is generally used for the introduction of post-tensioning cables, while the two smaller tendon ducts are simulating simple mono-strands, one being straight and the other curved. The objective was to detect the location of all the ducts by radar with special attention being paid to the curved duct. Measurements were initially performed without strands inside the smaller ducts in order to further challenge the technique. Half of the large duct was fully grouted and the other half partly grouted in order to evaluate the difference between fully filled and partly filled tendon ducts. The other simulated defects included a poorly vibrated or lower density concrete, represented by blocks of concrete with insufficient binder, low density concrete 

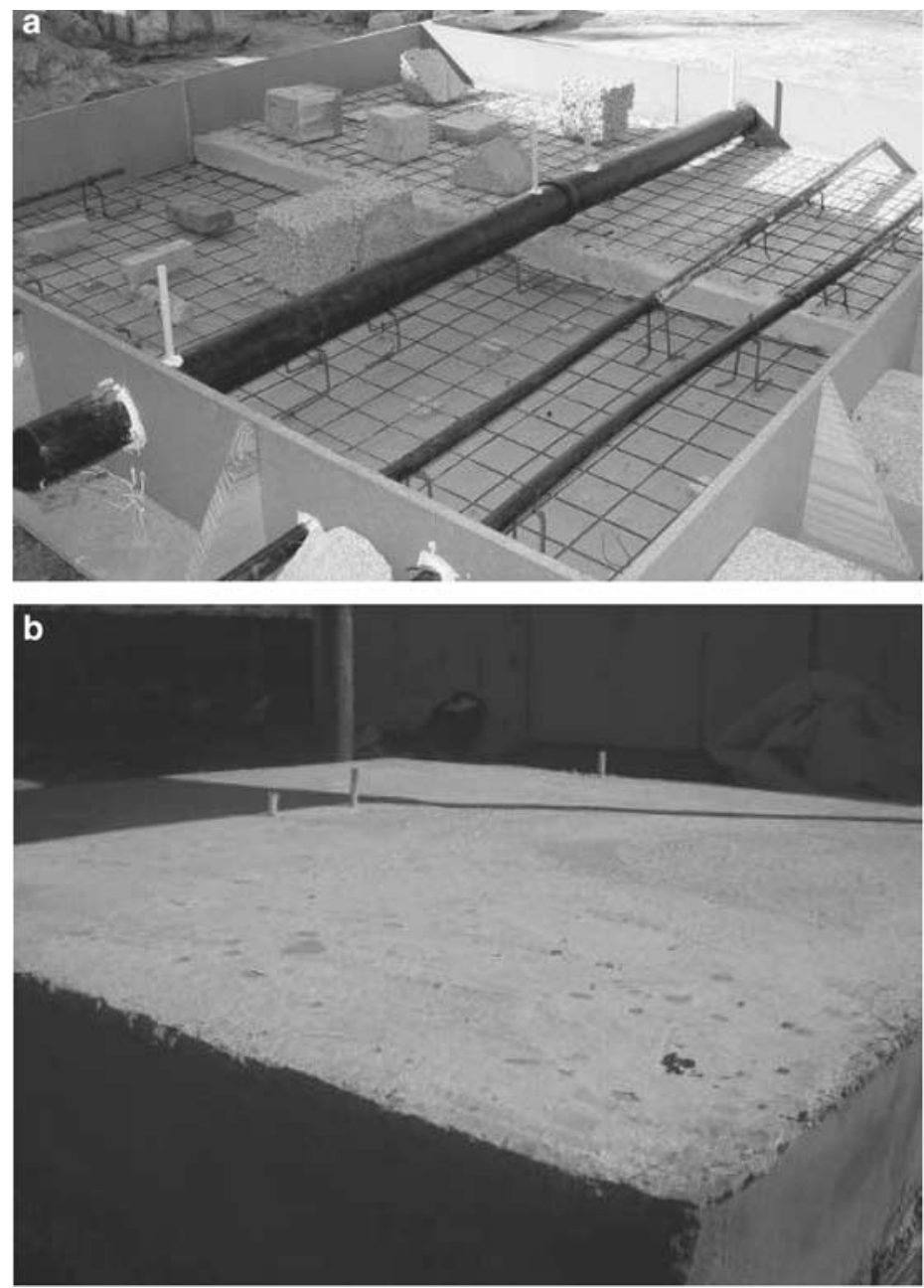

Figure 3: General view of the concrete specimen: (a) overview of the features and objects placed inside the specimen (before casting) and (b) final view of the slab after casting

(light-weight concrete), large voids and blocks with inclined surfaces. Furthermore, one empty glass bottle, one clay brick, wood and mortar prisms and two metallic bars were also inserted. In addition, a pre-cast concrete element (class C30/35; 70 mm thickness) was placed at the bottom of the specimen and that occupied half of the total area of the slab-test slab (Figure 4; the leading edge of the precast element can be seen in the centre of Figure 3a).

The remaining test area was filled with concrete (class C30/35) without any steel reinforcement bars, except for steel grids placed at the bottom of the specimen and on the upper surface of the precast slab in order to prevent premature cracking and to increase the specimen's resistance. The grid constituted steel wires with $2 \mathrm{~mm}$ diameter and square cells with $0.15 \mathrm{~m}$ offset. An additional steel part was inserted at the contact area with the precast element in order to be able to easily detect it in the radargrams.

The GPR system used for the acquisition was the RAMAC/GPR from MALA Geoscience. The system was equipped with a high-resolution antenna with a central frequency of $1.6 \mathrm{GHz}$ due to the small dimensions of the targets of this investigation. A digital hip chain was used as positioning system and as pulse trigger. 


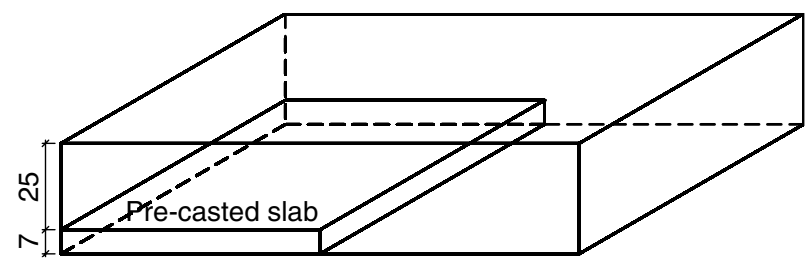

Figure 4: Location of the precast element inside the concrete specimen

In order to construct accurate 3D images, longitudinal 2D profiles closely spaced (50 $\mathrm{mm}$ apart) were drawn over the testing area (Figure 5a). Such a density of longitudinal profiles was essential in order to obtain a realistic 3D image and necessary to map all possible internal elements. Two areas of interest have been selected and are reported in Figure 5b: one constituted the part of the specimen (Area 1 in Figure 5b) where most of the deficiencies were located (poorly vibrated concrete, voids, etc) and half of the precast slab; another area (Area 2 in Figure 5b) considered Area 1 again and also the three simulated tendon ducts. Area 1 was acquired parallel to the tendon ducts, whereas radar acquisition in Area 2 was carried out in the direction perpendicular to the tendon ducts, in order to maximise the return of the signal reflected by them.

\section{Results and discussion}

2D profiles provided the depth and location information about elements located under each profile. All the profiles were later merged in a 3D volume, and time slices were extracted at different depths, which provided additional information such as shape and location of elements. The first area to be discussed is Area 1 followed by Area 2, where the results from $3 \mathrm{D}$ reconstruction present a clear advantage over $2 \mathrm{D}$ profiles in the case of bridge deck investigation.

\section{Results from Area 1}

The objective in this test area was to determine the position and shape of all internal elements, position of the opposite surface of the slab and the position of the precast slab. Figure 6 illustrates one radargram that shows the opposite surface at $7 \mathrm{~ns}$ of depth. The opposite side was detected by means of the hyperbolas reflected by the steel mesh, which was used to prevent concrete shrinkage, located at the bottom of the slab and almost in direct contact with the surface. Since these hyperbolas were considered to correspond to the bottom of the slab, the $7 \mathrm{~ns}$ were considered to correspond to the $0.32 \mathrm{~m}$ of thickness of the slab. This resulted in an average radiowave velocity of $92 \mathrm{~mm} / \mathrm{ns}$, which is low for concrete. Typical velocities in dry concrete are $90-130 \mathrm{~mm} / \mathrm{ns}$. The precast slab was detected in the first half of the radargram, at $5 \mathrm{~ns}$ from the surface, with a thickness around $1.5-2 \mathrm{~ns}(0.07-0.09 \mathrm{~m})$.

Figure 7 shows additional profiles from where poorly vibrated concrete/light-weight hollow concrete elements and the steel bar were successfully detected. From the radargrams, the length of the concrete elements was acquired with a rather satisfactory accuracy (the dashed boxes correspond to the dimensions of those elements). The height computed with the velocity of $92 \mathrm{~mm} / \mathrm{ns}$ resulted in lower values than the real ones, which seem to suggest that the velocity within these concrete elements is slightly higher than in the rest of the specimen (radiowaves in a very porous concrete have indeed a 


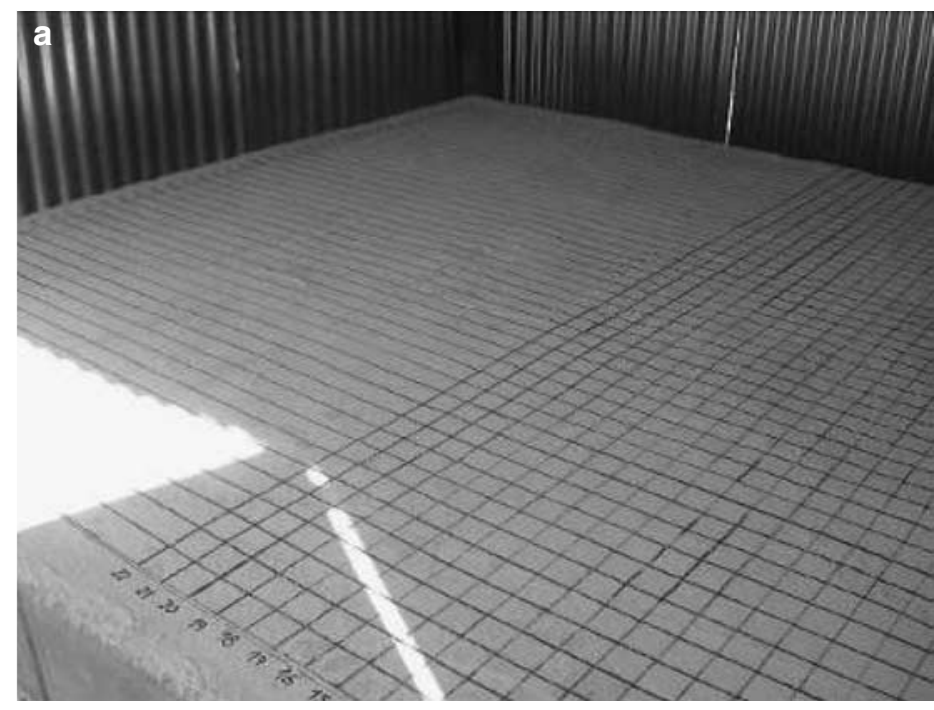

b

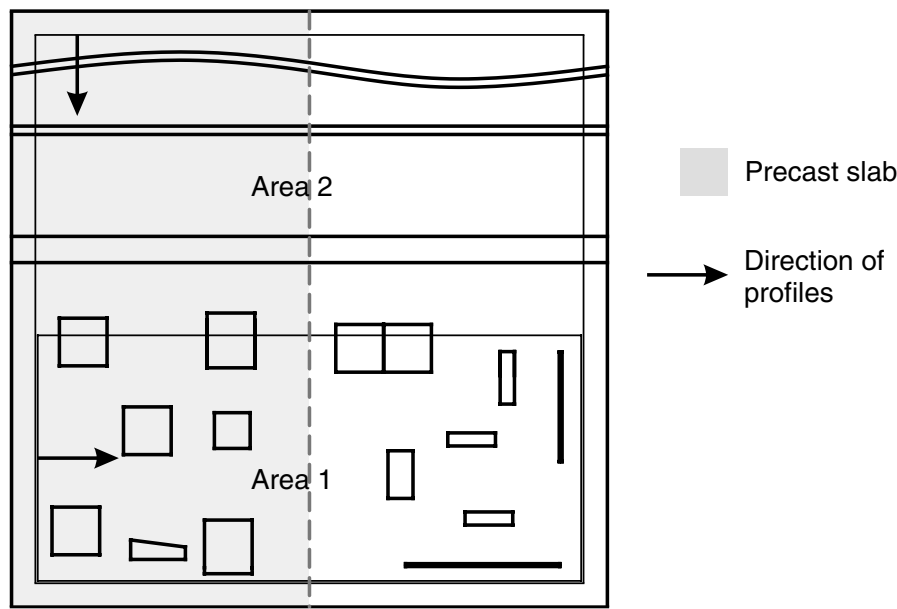

Figure 5: 3D measurements: (a) partial view of the grid drawn over the surface of the slab and (b) location of the areas of interest

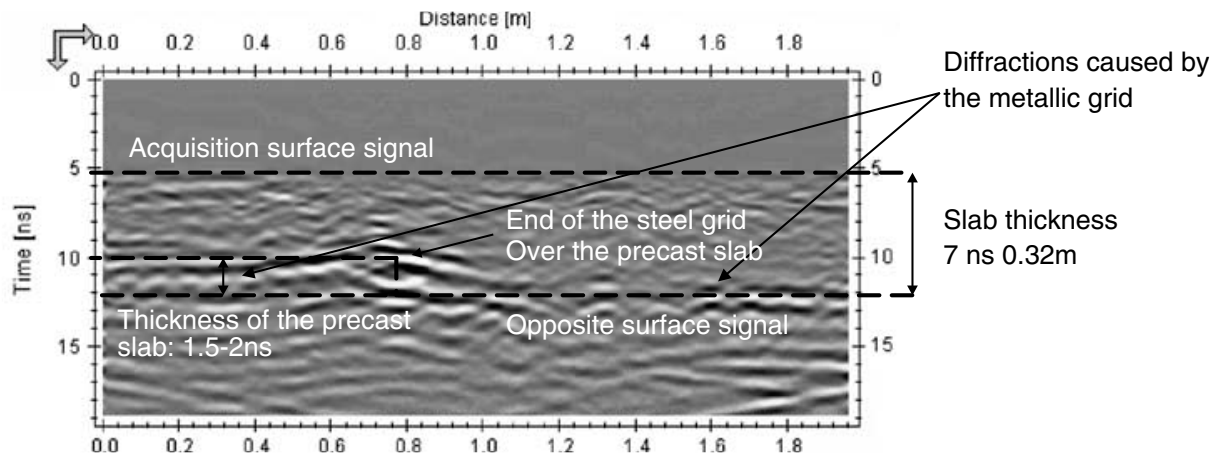

Figure 6: Detection of the opposite surface of the slab as well as the precast slab 


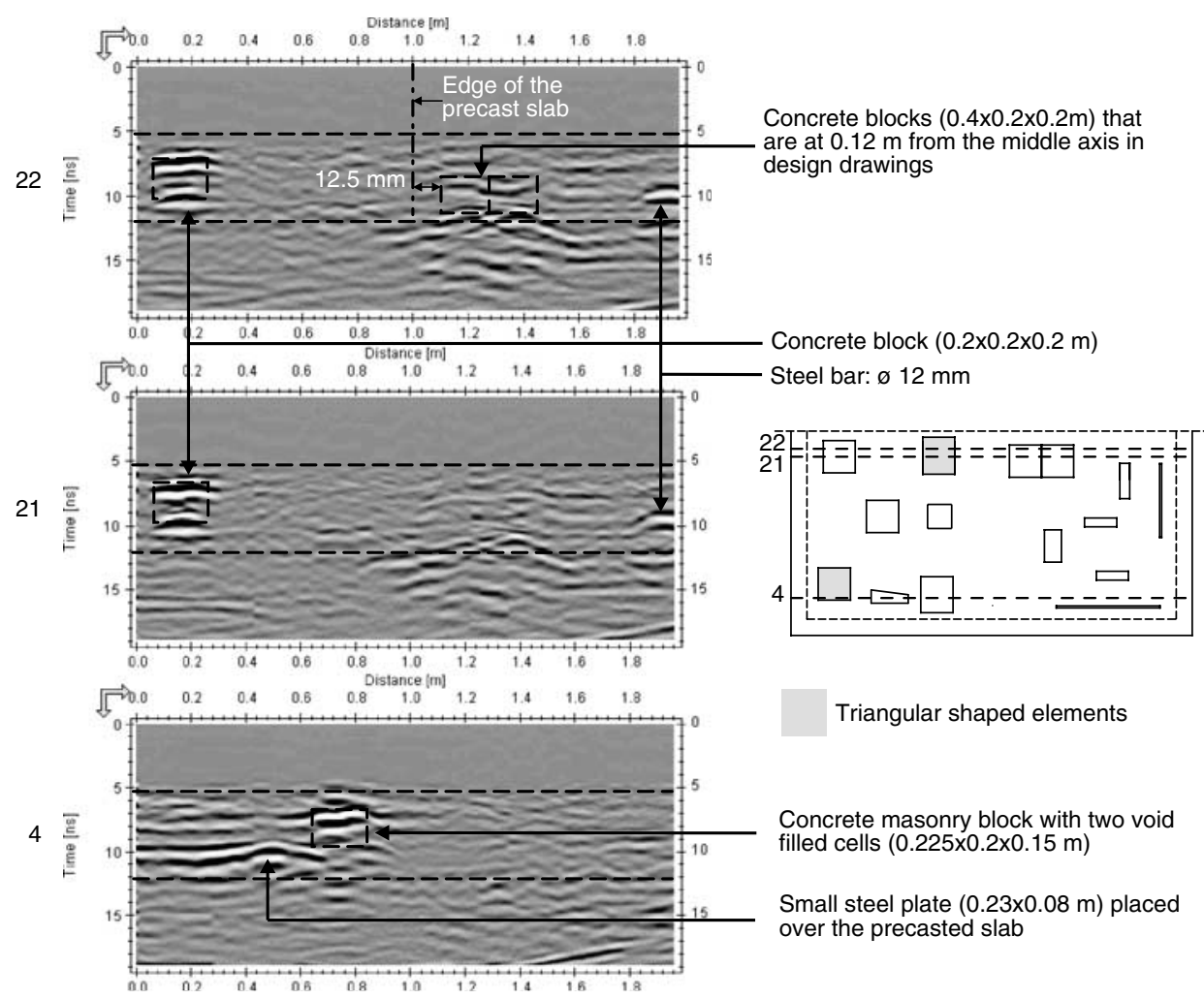

Figure 7: $2 \mathrm{D}$ profiles of the $22 \mathrm{nd}, 2 \mathrm{Ist}$ and 4 th acquisition lines, respectively, from top to bottom

higher velocity than in normal weight concrete). The location of the objects is also accurately described with respect to the central axis in case of the two concrete blocks in the 22nd profile. The radargram reported a depth of $0.125 \mathrm{~m}$, while the accurate value according to the specification drawings was located at $0.12 \mathrm{~m}$. One element in each profile from lines 4 and 22 was, however, not detected. It must be noted that these elements have a triangular shape (see also Figure 3a) and that the incident waves in such surfaces are scattered in a direction far from the receiver position. Thus, they are very difficult to detect.

Subsequently, the 3D image was built by performing linear interpolations between successive and closely spaced 2D radargrams. In this way, it was possible to obtain a more realistic representation of the data and, eventually, to better define the shapes and relative position of the objects previously detected with $2 \mathrm{D}$ profiles. The whole data were migrated in order to transform the diffraction hyperbolas in patterns closer to the shape of the objects they represent, and to extract slices at different depths to compare with the original specification drawings. Figure 8 presents two examples of time slices extracted from the main 3D volume. Generally, a good correlation between the dimensions and relative position of single objects and the original specification drawings was obtained. It is noted that the position of the elements can be slightly different from that originally planned due to deviations caused by concrete casting and vibration. The upper radargram of Figure 8 illustrates a case where the original positions (in white) are different from the actual positions detected by the antenna (in black). It is stressed that not all elements were detected, see the lower radargram of Figure 8. 


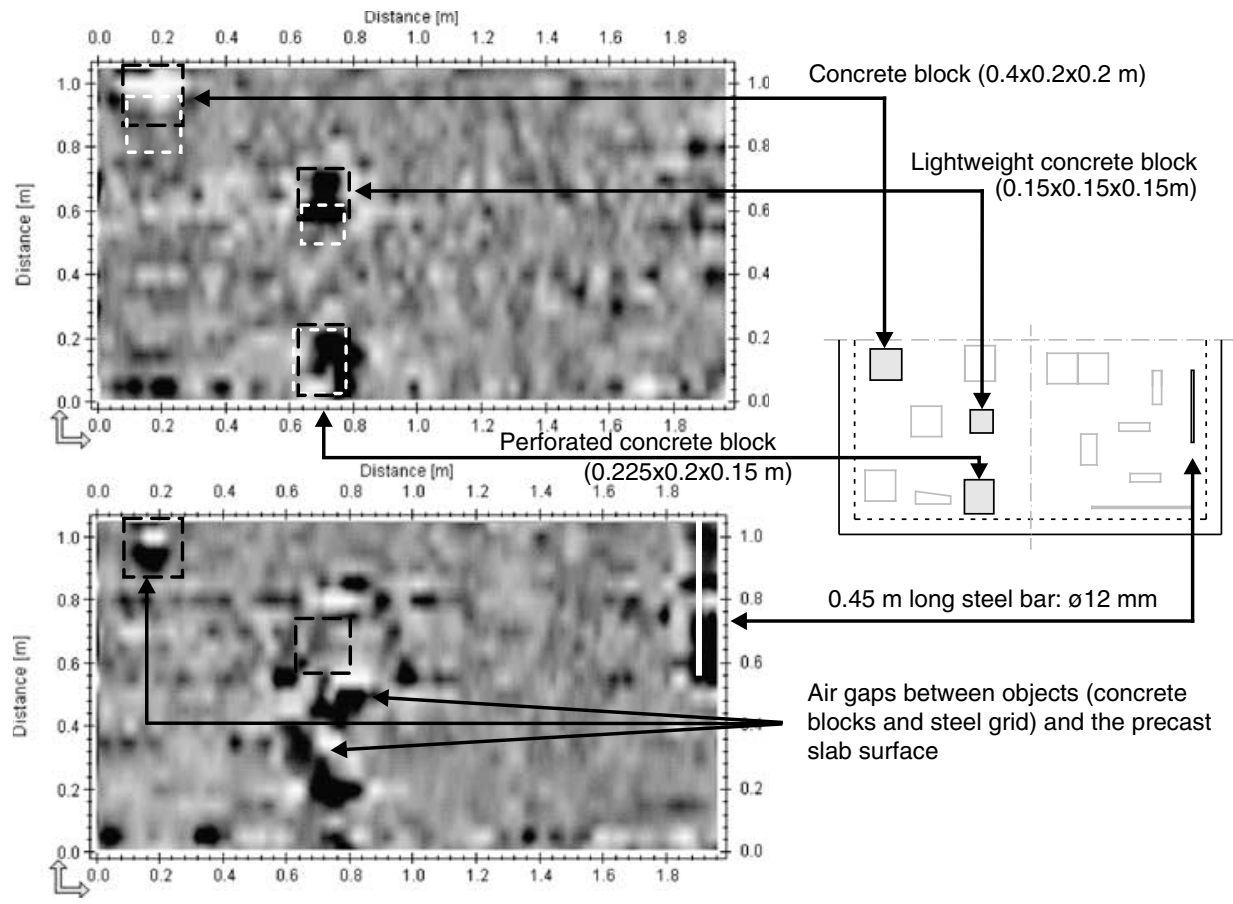

Figure 8: Time slices from the migrated 3D volume with accurately positioned objects that are not in their original location. Depth of the slices: 0.10 and $0.185 \mathrm{~m}$, respectively, from top to bottom

\section{Results from Area 2}

The second test area considered for the investigation corresponded to the whole slab surface (see Figure 5), with the objective of mapping the features located in the interior of the slab plus the three tendon ducts. Of particular interest was the correct acquisition of the curve-shaped tendon duct and of the larger duct, which had half and fully grouted sections.

The analysis of 2D profiles showed that the three tendon ducts were detected in all cases. The radargram in Figure 9 illustrates the three tendon ducts, where it appears that the two smaller diameter tendon ducts $(35 \mathrm{~mm})$ were detected by their upper interfaces, while in the case of the larger diameter tendon duct $(110 \mathrm{~mm})$, both interfaces were detected. This phenomenon is associated to the short wavelength $(\lambda)$ of the $1.6 \mathrm{GHz}$ antenna, which is $187.5 \mathrm{~mm}$, from where an expected resolution of $47 \mathrm{~mm}$ taken as $\lambda / 4$ (Forde, 2004). Since the diameter of the smaller tendon ducts is lower than $47 \mathrm{~mm}$, the signal from the upper interface of the smaller tendon ducts covers the lower interface signal. Only the signals reflected by the boundaries of the largest tendon duct were visible due to the fact that the distance between them was longer than the signal's expected resolution. This, however, depends on the contrast between the tendon duct and the infill material (air, grout or steel bar).

The analysis of the time slices illustrates the adequacy of the results. It was possible to identify the three tendon ducts as well as the position and shape of most of the other targets. The radargrams illustrated in Figure 10 clearly show several concrete blocks as well as the steel reinforcement bar that was perpendicular to the direction of radar acquisitions. The square/rectangular shape of the objects was quite reasonably detected after the migration of the data. Some of the objects placed in the interior of the concrete 


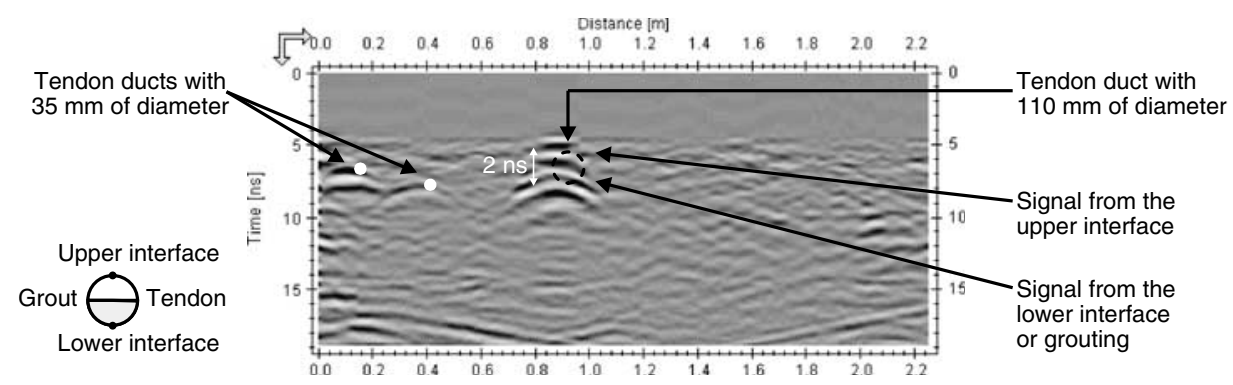

Figure 9: First profile from area 2 at $0.10 \mathrm{~m}$ from the border

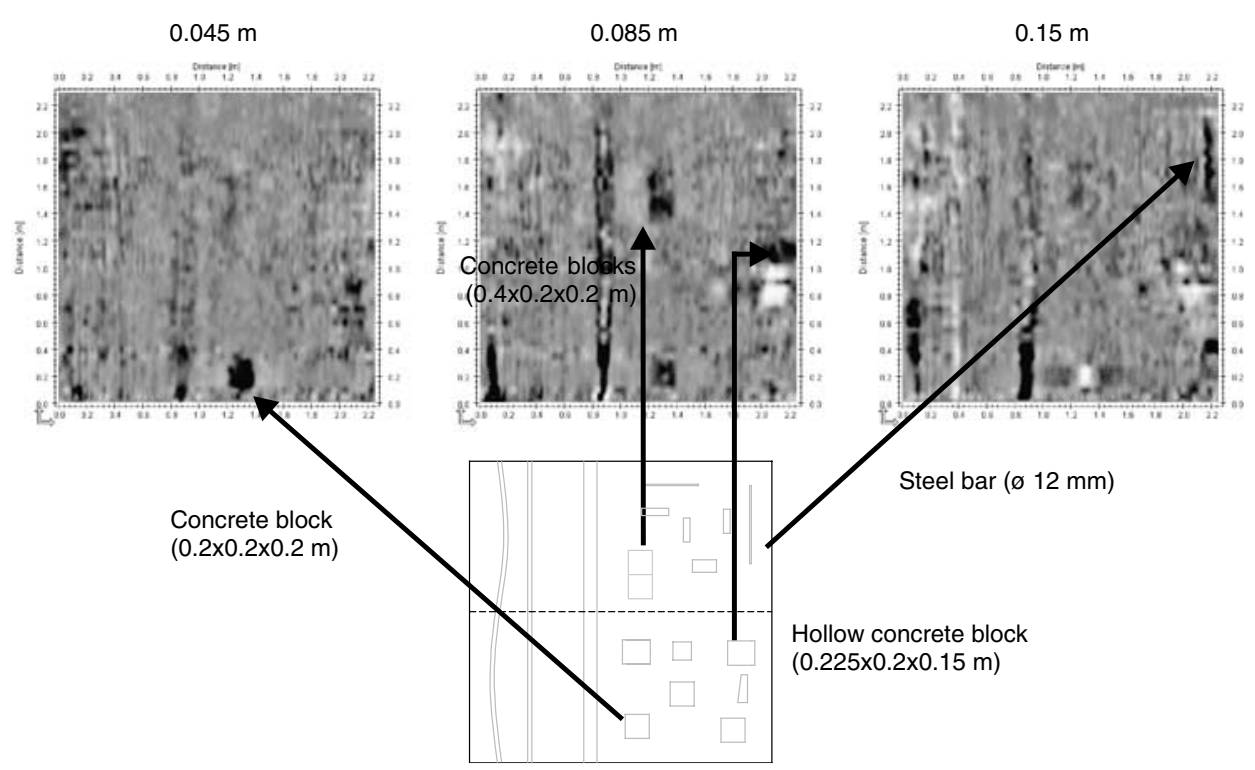

Figure 10: Time slices after migration where some of the concrete blocks and the steel bar perpendicular to the acquisition direction are observed

specimen, however, could not be identified because they were oriented parallel to the radar profiles (the plastic bottle and the clay brick), while others were too small or too deep to be reached by the radiowaves (light-weight concrete cube, mortar and wood prisms), and had insufficient contrast (concrete cube with $50 \mathrm{~mm}$ edge).

The mapping of the three tendon ducts is shown in Figure 11. All ducts were correctly detected and the curved duct was also well defined. Regarding the largest tendon duct, although it had been correctly detected, the intensity of the signal amplitude was not uniform along its entire length. As can be seen in the 2nd and 3rd radargrams, the radiowave energy seems to be higher in the bottom part of the section, where the tendon duct section was half grouted. The air in that area could explain the higher energy due to the higher contrast between dielectric constants of concrete $\left(\varepsilon_{\mathrm{r} \text {, concrete }}=6\right)$ and air $\left(\varepsilon_{\mathrm{r}, \text { air }}=1\right)$, which does not exist between concrete and grout. Thus, it is also possible to detect differently filled tendon duct sections by analysing the amplitudes of the reflected signals. 


\section{Application 2: Mapping of embedded elements in masonry walls with tomography}

\section{Description of the test specimen and methodology}

Two walls were built with three different masonry typologies using granite stone and lime mortar in order to simulate typical historic masonry typologies (Figure 12). The walls had three leaves, being the external leaves built with rubble, irregular or regular stone units, and the infill built with two different materials (loose gravel or stone and brick-mortared rubble). A void was simulated with a high-density polystyrene prism in the first wall, while a wood beam was placed in the second wall to simulate composite construction or a wooden tie beam. Both inclusions were placed vertically within the two walls.

The walls were built on top of a $50 \mathrm{~mm}$ thick concrete foundation slab. At the top of the walls, a thin layer of cover mortar was laid in order to protect the walls' infill from rain and dust. A small slope was provided to facilitate rainwater drainage. The dimensions of the walls were $1.22 \mathrm{~m}$ in height and $2.60 \mathrm{~m}$ in length. The thicknesses for the eastern wall (Wall 1) and for the western wall (Wall 2) were 0.68 and $0.56 \mathrm{~m}$, respectively. The masonry typology adopted in the external leaves of the walls (thickness of $0.20 \mathrm{~m}$ ) was (a) in the western side, rubble stone masonry with lime mortar joints; (b) in the eastern side, two different masonry typologies were used, namely, ashlars masonry with unfilled joints and irregular stone masonry with lime mortar.
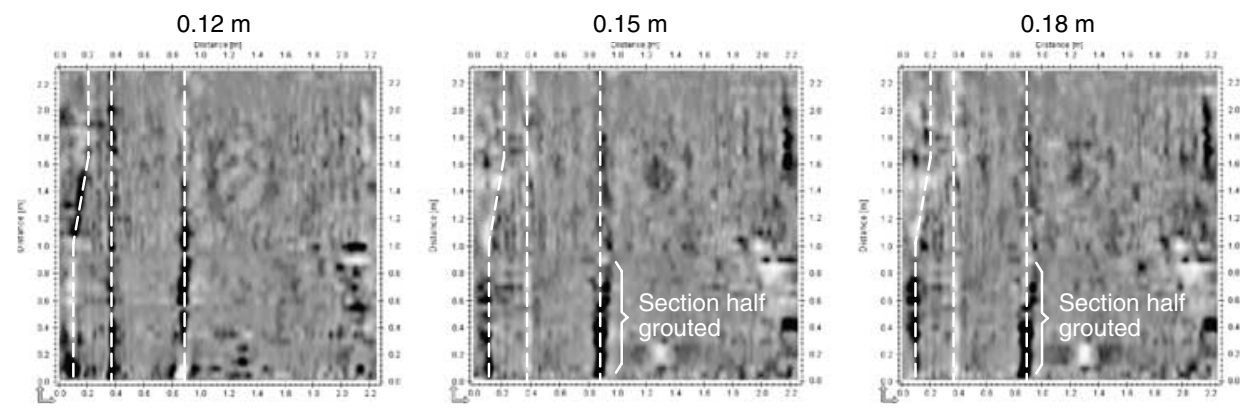

Figure I I: Radargrams showing the three tendon ducts

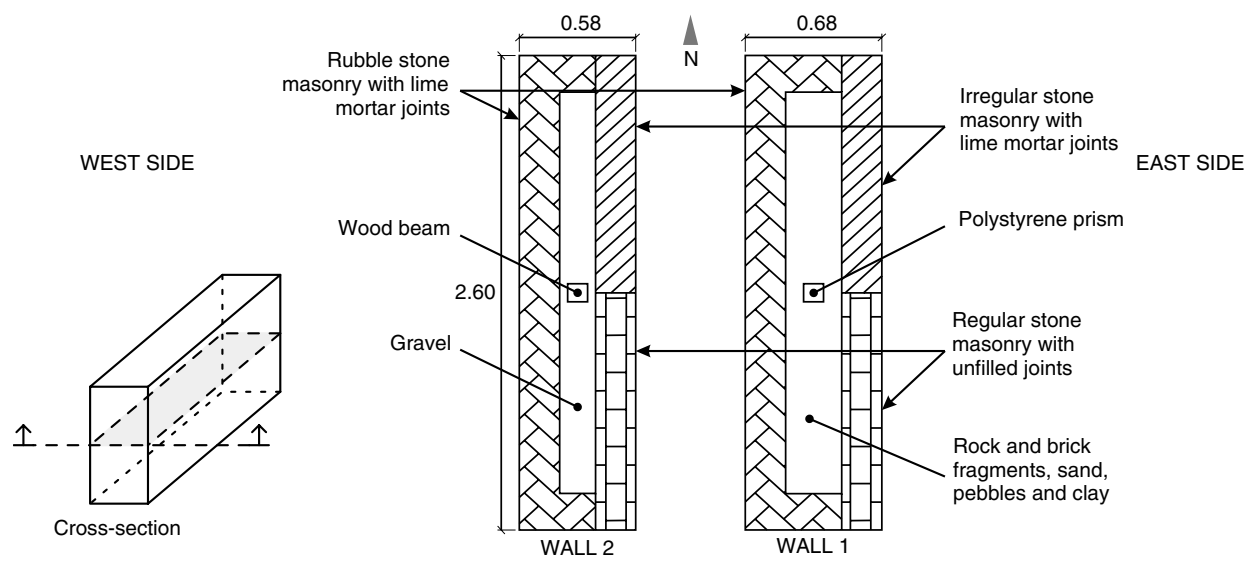

Figure 12: Horizontal cross-sections of the two masonry walls built (m) 
For Wall 1, the infill was made of mortared rock, brick fragments, sand pebbles and clay in order to simulate non-homogeneous infill material of low strength. In Wall 2, the infill was made of loose gravel, $20-30 \mathrm{~mm}$ in diameter, in order to simulate a cohesionless non-mortared infill.

The objects embedded in the walls had the following dimensions: $95 \times 80 \times 400 \mathrm{~mm}$ for the high-density polystyrene prism (Figure 13a) and $65 \times 65 \times 1000 \mathrm{~mm}$ for the wooden beam (Figure 13b). The objectives of the present investigation were to detect the different masonry thicknesses and to detect the wood and polystyrene elements placed inside the walls.

\section{Results and discussion of 2D acquisitions (target location)}

The investigation of the two masonry walls was carried out with the RAMAC/GPR system from MALA Geoscience. A $1.6 \mathrm{GHz}$ frequency antenna was used for all measurements, and a digital hip chain was used as the triggering and positioning
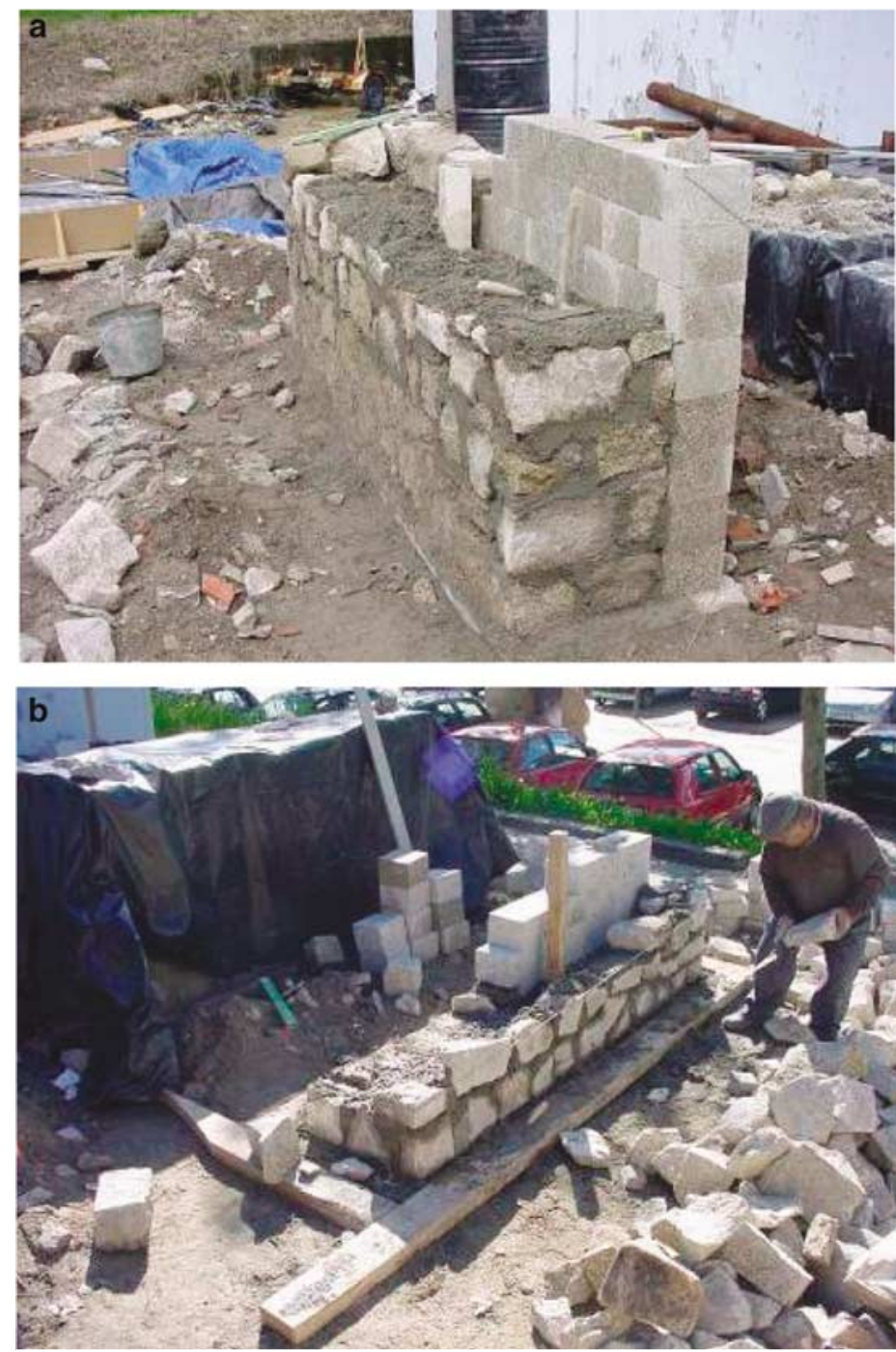

Figure 13: View of the embedded objects: (a) polystyrene prism and (b) wood beam 
device. This configuration was preferred over the survey wheel due to the irregularity of the surface. The average radiowave velocity was evaluated with the antenna, in the centre of the masonry panels, oriented towards the east and a steel plate placed over the opposite surface. The acquisition in time resulted in an average radiowave velocity around $120 \mathrm{~mm} / \mathrm{ns}$ in both the walls.

Several horizontal profiles were carried out on the eastern sides of both walls (with two external leaves of regular and irregular masonry). The centre of the antenna started measuring at $0.15 \mathrm{~m}$ from one end and terminated at $0.10 \mathrm{~m}$ from the other end. This resulted in profiles with a length of about $2.25 \mathrm{~m}$. The horizontal profiles were separated by $0.050 \mathrm{~m}$.

Figure 14 represents a radargram from Wall 1 in the upper part of the wall. The data have been filtered and a gain function was applied to enhance the diffractions. It is possible to recognise the regular masonry panel by the horizontal signal it has produced at the beginning of the profile, while the second external leave is detected via the hyperbolas that spread in the first nanoseconds. The interface between the first leaf and the infill material was clearly defined at an average depth of $3.5 \mathrm{~ns}$, characterised by a strong reflection due to air voids caused by the deficient contact between stone and infill. Assuming the average wall velocity $(120 \mathrm{~mm} / \mathrm{ns})$, the final thickness of the stone layer was estimated at $0.21 \mathrm{~m}$ (error of 5 per cent with respect to the prescribed thickness). No radargram was, however, obtained that clearly showed the signal from the polystyrene prism.

With respect to Wall 2, the interface between the first stone panel was detected (see Figure 15), with a clear distinction between regular and irregular masonry at $1.0-1.1 \mathrm{~m}$ from the beginning of the profile. The irregularity of the signal later indicates the interface with the irregular masonry panel. The wooden beam placed inside the infill was correctly detected by a rather strong diffraction at $\sim 1.1 \mathrm{~m}$ from the beginning of the profile. The signal from the opposite surface was also detected. The second interface (infill/opposite external masonry leaf), however, could not be detected.

\section{Results and discussion of tomography (target mapping)}

2D reflection radargrams were of limited use in the assessment of characteristic features of the timber beam and the polystyrene prism embedded in the masonry walls. In an attempt to better assess the nature and shape of these objects, transmission measurements were carried out in the area where those objects existed. Transmission measurements

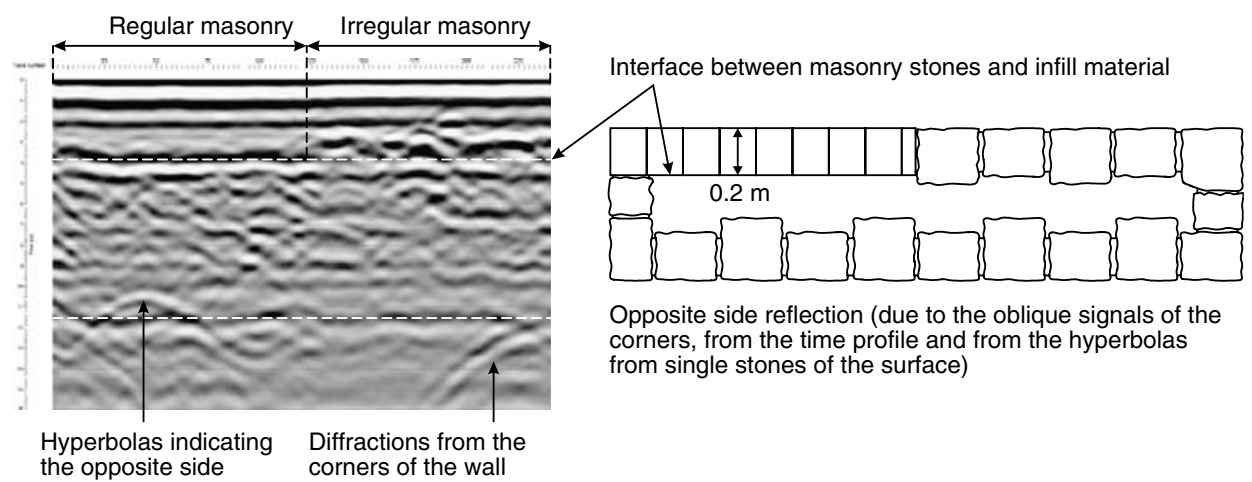

Figure 14: Ninth profile on Wall I at $0.49 \mathrm{~m}$ with the $1.6 \mathrm{GHz}$ antenna 
result in velocity and attenuation tomograms that can help to identify the nature and shape of the embedded elements.

The measurements were carried out in both the walls with two $1.6 \mathrm{GHz}$ antennas. The investigation area was selected around the location of the embedded elements.

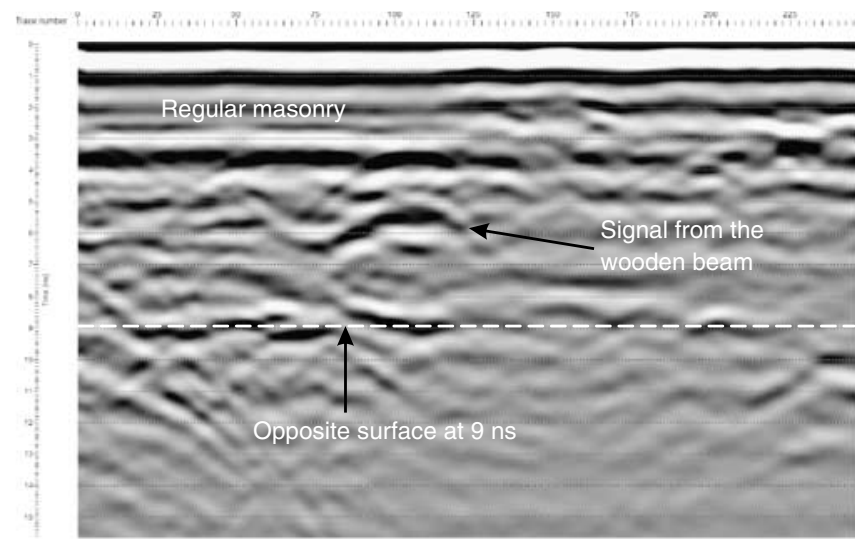

Figure 15: Radargram at $0.29 \mathrm{~m}$ from the concrete base with the $1.6 \mathrm{GHz}$ antenna

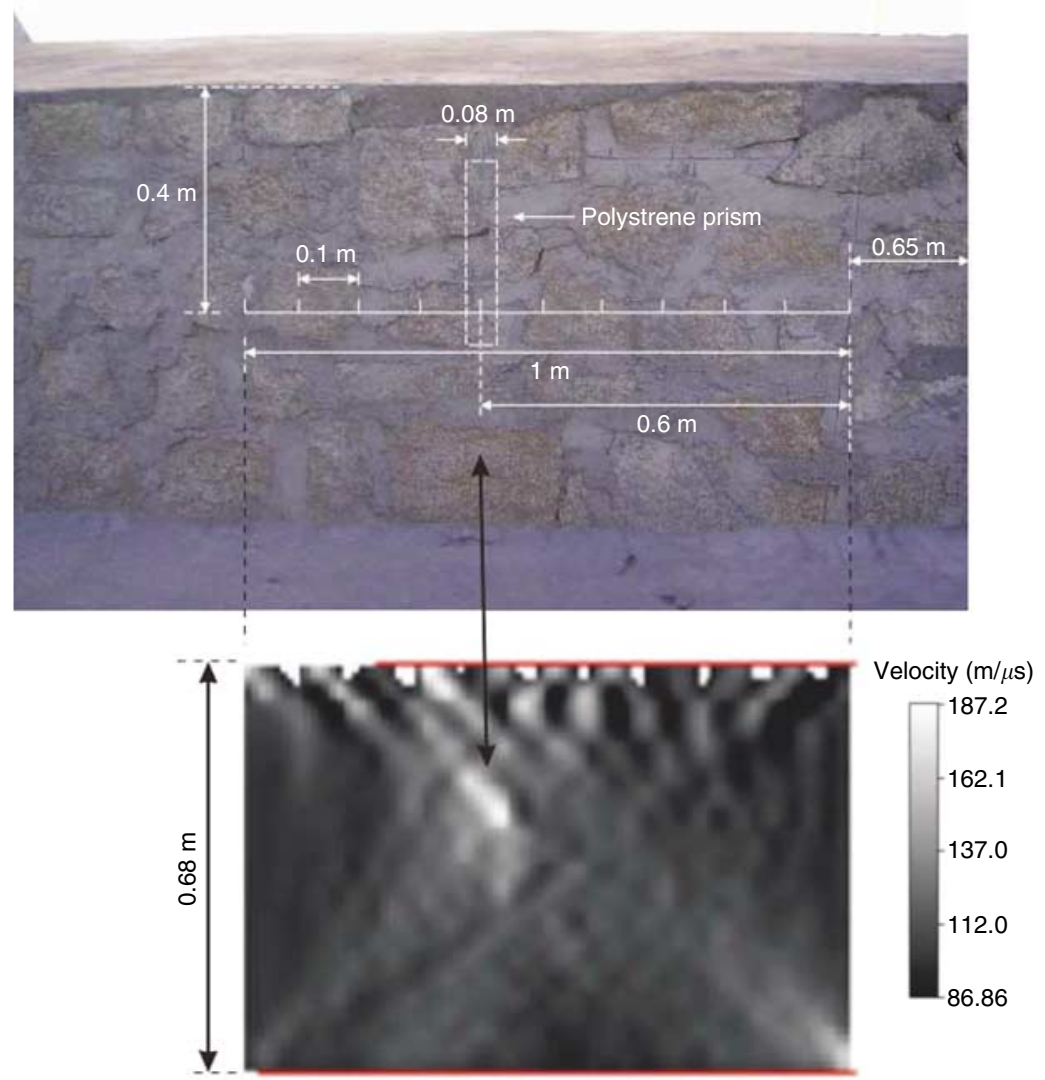

Figure 16: Tomography in Wall I. Fixed stations for the transmitter antenna and relative position of the polystyrene prism in the grid of measurements and, below, the velocity tomogram 
With respect to Wall 1 (with the polystyrene prism inclusion), the section of interest was located $0.40 \mathrm{~m}$ below the top of the wall and consisted of an area of $1.00 \times 0.68 \mathrm{~m}$ as illustrated in Figure 16. The transmitter was sequentially fixed at 11 stations separated by $0.10 \mathrm{~m}$, while the receiver was performing 11 continuous profiles at the opposite side of the wall. WinTomo software (proprietary of MALA Geoscience) was used to process the data and obtain the final velocity and attenuation tomograms.

The final velocity tomogram obtained from the investigation in Wall 1 is illustrated in Figure 16 and shows an average velocity lower than $120 \mathrm{~mm} / \mathrm{ns}$. The borders of the tomogram were characterised by a substantial number of typical artefacts and other side effects, which should not be taken into consideration. A small area exhibiting a very high velocity, around $180 \mathrm{~mm} / \mathrm{ns}$, was located in the centre of the tomogram and corresponds to the position of the polystyrene prism. From the tomogram, it can be perceived that the speed of propagation of radiowaves within polystyrene is close to the velocity in air (which is why this material is often used for air substitution when simulating air voids inside structures). The area with high-velocity radiowaves corresponds to an area about 19 per cent smaller than the area of the polystyrene prism.

With respect to Wall 2 (with the wooden beam inclusion), the section of interest was located $0.40 \mathrm{~m}$ below the top of the wall and consisted of an area of $0.80 \times 0.58 \mathrm{~m}$ as illustrated in Figure 17. The transmitter was sequentially fixed at nine stations separated

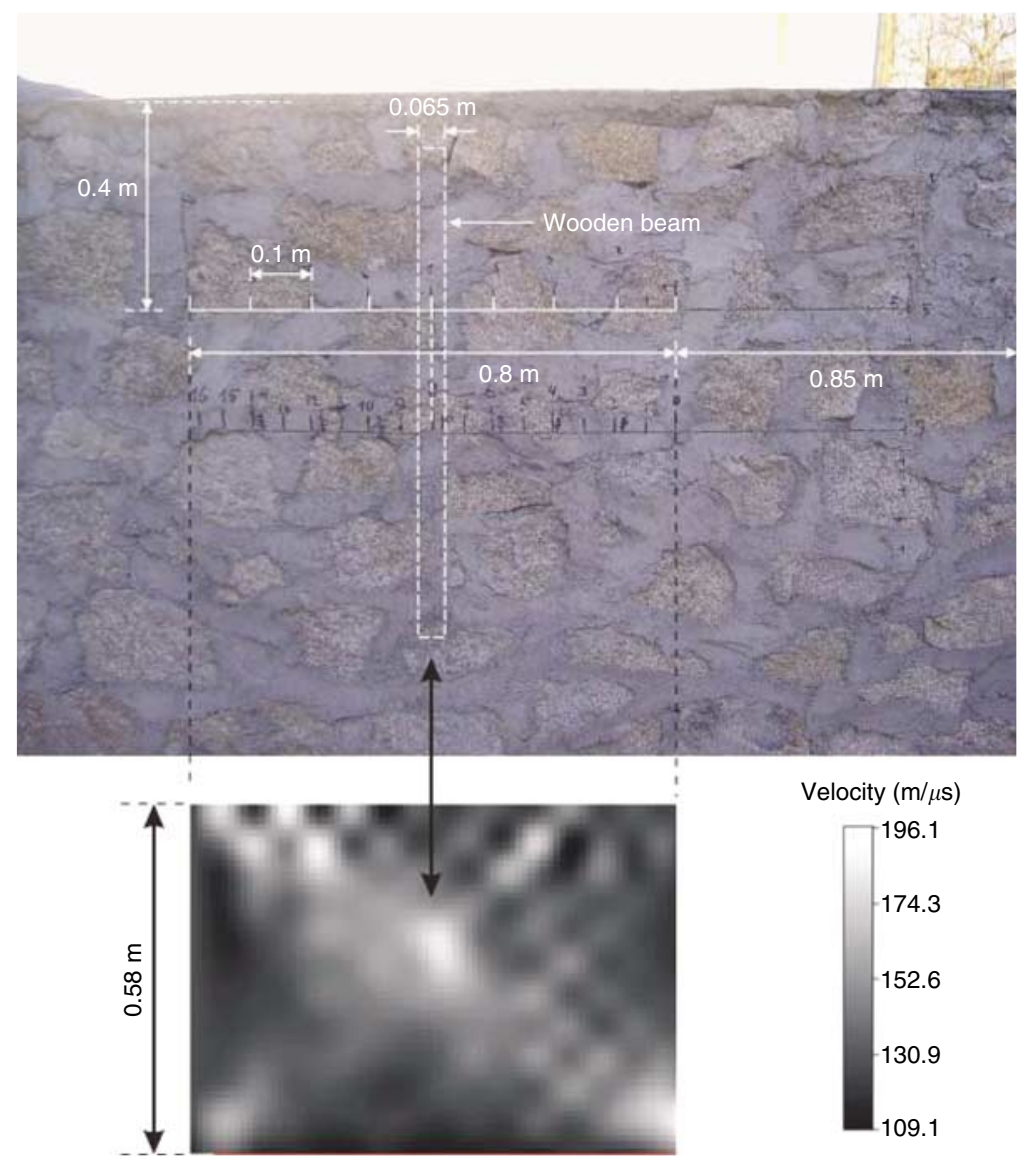

Figure 17: Tomography in Wall 2. Fixed stations for the transmitter antenna and relative position of the wooden beam in the grid of measurements and, below, the velocity tomogram 
by $0.10 \mathrm{~m}$, while the receiver was performing nine continuous profiles on the opposite side of the wall. The final velocity tomogram obtained from the investigation in Wall 2 is also illustrated in Figure 17. The major part of the tomogram exhibits an average velocity around $140 \mathrm{~mm} / \mathrm{ns}$. The area that was interpreted as being from the wooden beam corresponded well to its geometrical location and exhibited a very high velocity, around $190 \mathrm{~mm} / \mathrm{ns}$, close to the velocity found in polystyrene. The borders and interior of the tomogram are, however, characterised by a substantial number of artefacts and other side effects that significantly affect the quality of the data. In this case, the resolution of the tomogram was limited due to the reconstruction algorithms used by the software as already described by other authors (Valle et al., 1999). The area of the wooden beam cross-section estimated from the tomogram resulted in an area 17 per cent larger than the real area of the wooden beam. Obviously, in both cases, these errors depend on the size of the inclusion and must be related to the antenna resolution.

\section{CONCLUSIONS}

The use of GPR with 3D reconstruction showed good potential in geometrical evaluation of structural elements as well as in the mapping of typical defects and inclusions frequently found in structures. In the case of prestressed concrete elements, the location of tendon ducts, including the curvature of a curved tendon duct, was correctly assessed.

Nevertheless, not all targets could be resolved due to their unfavourable orientation with respect to the direction of the profiles. Because the profiles started and ended $0.10-0.15 \mathrm{~m}$ after and before the specimen end, some objects located very close to the edges of the specimen were also not detected. Moreover, the poor contrast between materials resulted in poor reflectivity and thus weak detection, particularly in the case of a light-weight concrete specimen placed inside a concrete mass. Finally, triangular-shaped inclusions did not reflect favourably on detection by the radar signals.

Radar tomography used for fine target assessment, subsequent to target detection by reflection mode, was shown to be a good combination. With respect to the detection capacities of this configuration, a wooden beam and a polystyrene prism (representing a void) inside masonry were clearly detected. The tomography carried out in two masonry walls resulted in satisfactory results. This methodology was partly limited by the number of artefacts which appeared in the results that partially masked the targets of the investigation, especially in the case of the wooden beam.

The adopted antenna, with a central frequency of $1.6 \mathrm{GHz}$, exhibited very good resolution and high accuracy for $3 \mathrm{D}$ reconstruction and tomography. These advanced techniques have been already used competitively by construction companies, design offices and structure and infra-structures owners who seek accurate geometrical and condition information by using cost-effective solutions, at a moderate budget, when compared with construction, repair or rehabilitation costs. Despite the good results shown in the paper for the described applications, there is still a need to improve positioning systems for more accurate acquisitions and to improve software tomography algorithms and signal processing.

\section{Acknowledgements}

The first author would like to acknowledge the support from the 'Sustainable Bridges' European project, grant number FP6-PLT-01653 (www.sustainablebridges.net), while 
the second author acknowledges the partial funding of this work by FCT through the scholarship POCTI SFRH/BD/6409/2001.

\section{References}

Becht, A., Tronicke, J., Appel, E. and Dietrich, P. (2004) 'Inversion strategy in crosshole radar tomography using information of data subsets', Geophysics, 69(1), 222-230.

Binda, L., Lualdi, M., Saisi, A., Zanzi, L., Gianinetto, M. and Roche, G. (2003a) 'NDT applied to the diagnosis of historic buildings: A case history', 10th International Conference Structural Faults \& Repair, London, UK, CD-ROM

Binda, L., Saisi, A., Tiraboschi, C., Valle, S., Colla, C. and Forde, M. (2003b) 'Application of sonic and radar tests on the piers and walls of the Cathedral of Noto', Construction and Building Materials, 17(8), 613-627.

Buyukozturk, O. (1998) 'Imaging of concrete structures', NDT \& E International, 31(4), 233-243.

Daniels, D.J. (2004) Ground Penetrating Radar, 2nd edn. IEE, Radar, Sonar, Navigation and Avionics Series 15, Institution of Electrical Engineers, London, UK.

Doerksen, K. (2002) Improved Optical Positioning for GPR Based Structure Mapping, 9th International Conference On Ground Penetrating Radar (GPR2002), Santa Barbara, CA, USA, pp. 63-67.

Forde, M.C. (2004) Ground Penetrating Radar, Introduction to Non-destructive Evaluation Technologies for Bridges Conference, Transportation Research Board Conference, Washington DC, USA, p. 20.

Groenenboom, J., Van Der Kruk, J. and Zeeman, J.H. (2001) 3D GPR Data Acquisition and the Influence of Positioning Errors on Image Quality, EAGE 63rd Conference and Technical Exhibition, Amsterdam, The Netherlands. p. 4.

Hugenschmidt, J. (2002) 'Concrete bridge inspection with a mobile GPR system', Construction and Building Materials, $16(3), 147-154$.

Kak, A.C. and Slaney, M. (1988) Principles of Computerized Tomographic Imaging, Institute for Electrical and Electronic Engineers Press, London, UK.

Kohl, Ch., Krause, M., Maierhofer, Ch., Mayer, K., Wöstmann, J. and Wiggenhauser, H. (2003) '3-visualisation of NDT data using a data fusion technique', Insight - Non-Destructive Testing and Condition Monitoring, 45(12), 800-804.

Krause, M., Maierhofer, C. and Wiggenhauser, H. (1995) Thickness Measurement of Concrete Elements using Radar and Ultrasonic Impulse Echo Techniques, 6th International Conference Structural Faults and Repair, London, UK, p. 17-24.

Lualdi, M., Zanzi, L. and Binda, L. (2003) Acquisition and Processing Requirements for High Quality 3D Reconstructions from GPR Investigations, International Symposium Non-Destructive Testing in Civil Engineering (NDT-CE), Berlin, Germany, CD-ROM.

Maierhofer, C., Brink, A., Röllig, M. and Wiggenhauser, M. (2003) 'Detection of shallow voids in concrete structures with impulse thermography and radar', NDT \& E International, 36(4), 257-263.

Tronicke, J., Dietrich, P. and Appel, E. (2002) 'Quality improvement of crosshole georadar tomography: Pre- and postinversion data analysis strategies', European Journal of Environmental and Engineering Geophysics, 7, 59-73.

Valle, S., Zanzi, L. and Lenzi, G. (2000) 2D and 3D Focusing of Ground Penetrating Radar Data for NDT, 8th International Conference on Ground Penetrating Radar, Gold Coast, Queensland, Australia, 23-26 May, pp. 157-162.

Valle, S., Zanzi, L. and Rocca, F. (1999) 'Radar tomography for NDT: Comparison of techniques', Journal of Applied Geophysics, 41(2-3), 259-269. 